\title{
Impact of nanoparticle albumin-bound paclitaxel on microscopic structure and immunohistochemical expression of transforming growth factor- $\beta 1$ in the renal cortex of rat diabetic nephropathy
}

\author{
Shireen A. Mazroa*, Samar A. Asker \\ Department of Histology and Cell Biology, Faculty of Medicine, Mansoura University, Egypt
}

Received: 08 May 2016

Accepted: 14 May 2016

\section{*Correspondence:}

Dr. Shireen A. Mazroa,

E-mail: shireenmna@yahoo.com

Copyright: $\odot$ the author(s), publisher and licensee Medip Academy. This is an open-access article distributed under the terms of the Creative Commons Attribution Non-Commercial License, which permits unrestricted non-commercial use, distribution, and reproduction in any medium, provided the original work is properly cited.

\begin{abstract}
Background: Diabetic nephropathy is a serious complication of diabetes. A low dose of paclitaxel drug ameliorates fibrosis in different diseases. Nano-particle albumin-bound paclitaxel (nab-paclitaxel) is a novel formula of paclitaxel approved in many countries.

Methods: This study aimed to investigate the effect of nab-paclitaxel on microscopic structure and immunohistochemical expression of transforming growth factor- $\beta 1$ (as a fibrogenic mediator) in the renal cortex of rat diabetic nephropathy. Forty five adult rats were divided into; group I (control), group II (receiving nab-paclitaxel), group III (diabetic) and group IV (diabetic rats receiving nab-paclitaxel). After 4 weeks, kidneys were prepared for light microscopy and TGF- $\beta 1$ immunohistochemical study.

Results: Renal cortex in group II had a microscopic structure similar to group I. TGF- $\beta 1$ immune-reaction was negative in group I and II. Group III showed microscopic diabetic changes as hypertrophied renal corpuscles, expanded mesangial matrix, degenerated tubules, interstitial inflammatory cells infiltration, and glomerular and tubulo-interstitial fibrosis. A positive TGF- $\beta 1$ immune-reaction was detected in renal corpuscles and tubules. In group IV, diabetic changes were relatively ameliorated with decreased TGF- $\beta$ 1immune-expression.

Conclusions: Nab-paclitaxel partially ameliorated microscopic structural changes in renal cortex of rats with diabetic nephropathy and decreased TGF- $\beta 1$ immune-expression, suggesting a partial reno-protective effect of nab-paclitaxel in diabetic nephropathy.
\end{abstract}

Keywords: Diabetic nephropathy, immunohistochemistry, Light microscopy, Nab-paclitaxel, Renal cortex, TGF- $\beta 1$

\section{INTRODUCTION}

Diabetic nephropathy is one of the most serious complications of diabetes that may lead to chronic renal failure. ${ }^{1}$ Diabetic nephropathy refers to a characteristic set of microscopic structural changes in renal glomeruli and tubules accompanied with fibrosis. ${ }^{2}$ Over the past several years, transforming growth factor-beta-1 (TGF$\beta 1$ ) has emerged as having a key role in the fibrotic response in diabetic nephropathy. ${ }^{3,4}$ In human mesangial cells, an increase in the concentration of TGF- $\beta 1$ has been found to induce $\alpha$-SMA and collagen type I expression. ${ }^{5}$ Therefore, the use of TGF- $\beta 1$ inhibitors could provide a possible therapeutic strategy in diabetic nephropathy. It has been demonstrated that a low dose of a drug known as paclitaxel can ameliorate fibrosis in the tissue through the inhibition of TGF- $\beta 1$ signaling. ${ }^{6}$

Paclitaxel is a natural alkaloid that was originally isolated from the bark of Taxus brevifolia tree in the western region of the United States. ${ }^{7}$ Paclitaxel is one of the most widely used anticancer drugs that is used successfully for the treatment of various cancers as metastatic breast cancer, advanced ovarian cancer, non-small-cell lung cancer and Kaposi's sarcoma. ${ }^{8}$ Paclitaxel is a highly hydrophobic agent; therefore, the available products of 
paclitaxel are dissolved in polyethylated castor oil (Cremophor $\mathrm{EL}^{\circledR}$ ) and ethanol to improve the hemodynamics of the drug. However, such solvents are believed to contribute to some of the toxicities commonly associated with paclitaxel. ${ }^{9}$ Using the nanotechnology, a novel solvent-free formula of paclitaxel, known as nanoparticle albumin-bound paclitaxel (nab-paclitaxel, Abraxane $^{\circledR}$ ), has been recently approved in many countries. Nab-paclitaxel is a colloidal suspension of 130 nanometer particles, homogenized with serum albumin, by which it is possible to infuse higher doses of the drug than the standard dose used in the slandered paclitaxel therapy. ${ }^{10}$ Clinical studies have shown that nab-paclitaxel is significantly more effective than the standard solvent containing paclitaxel with almost double the response rate and increased survival rate in cancer patients. ${ }^{11}$

Many studies demonstrated a promising use of the standard solvent containing formula of paclitaxel in controlling fibrosis and treatment of non-cancer diseases such as skin disorders, coronary artery restenosis, axon regeneration, and hepatic fibrosis. ${ }^{6,12-14}$ However, to date, the effect of the solvent free nab-paclitaxel on diabetic nephropathy and the associated fibrosis has not been investigated.

Therefore, the aim of the present work was to investigate the effect of nanoparticle albumin-bound paclitaxel (nabpaclitaxel) on the microscopic structural changes and the immunohistochemical expression of TGF- $\beta 1$, as a fibrogenic mediator, in the renal cortex of adult rat model of diabetic nephropathy.

\section{METHODS}

\section{Animal study}

All the procedures in the study were performed in accordance with the institutional research board (IRB) committee in our institute. Forty five adult male albino rats (100-120 days old and 200-250 gm weight) were maintained with water and food ad libidum. Twenty rats were subjected for induction of diabetes.

\section{Induction of diabetes}

Streptozotocine (STZ) drug (Sigma, St. Louis Mo, USA) was used to induce diabetes. Rats were starved for $16 \mathrm{~h}$ then injected once into the tail vein with STZ $(60 \mathrm{mg} / \mathrm{kg})$ dissolved in $0.1 \mathrm{M}$ sodium citrate buffer $\mathrm{pH} 4.5{ }^{15}$ Rats received $5 \%$ sucrose for $48 \mathrm{~h}$ to guard against fatal hypoglycaemia. Two days later, blood was drawn from the retro-orbital sinus, and the diabetic state was confirmed by the measurement of fasting blood glucose concentration with a glucometer (Accu-Check instant, Boehringer Mannheim Corporation, Indianapolis, IN, USA). Rats with fasting blood glucose levels over 250 $\mathrm{mg} / \mathrm{dl}$ were considered diabetic and were included in the study $(n=18)$. Diabetic rats were not treated with insulin to avoid any possible effect of insulin that may interfere with the results of the study. ${ }^{16}$

\section{Animal groups}

The animals used in the study were divided into 4 groups. Group I $(n=15)$ included control rats; 5 rats did not receive any treatment, 5 rats received intravenous injection of $1 \mathrm{ml} / \mathrm{kg}$ of $0.1 \mathrm{M}$ sodium citrate buffer $\mathrm{pH}$ 4.5 (the solvent of STZ), and the remaining 5rats received intravenous injection of $1 \mathrm{ml} / \mathrm{kg}$ of $0.9 \%$ normal saline (the solvent of nab-paclitaxel). Group II $(n=10)$ included rats receiving nab-paclitaxel (ABRAXANE ${ }^{\circledR}$, Abraxis BioScience, Inc, LA, USA). The rats in this group were first anesthetized with intra-peritoneal injection of Nembutal $(20 \mathrm{mg} / \mathrm{kg}$ body weight), then they received nab-paclitaxel in a dose of $6 \mathrm{mg} / \mathrm{kg}$ body weight dissolved in $1 \mathrm{ml}$ of $0.9 \%$ normal saline by slow intravenous infusion over 10 minutes once per week. ${ }^{17}$ Group III $(n=9)$ included diabetic rats. Group VI $(n=9)$ included diabetic rats receiving nab-paclitaxel in a dose similar to group II.

\section{Obtaining the samples and tissue preparation}

After 4 weeks, animals were anaesthetized by intraperitoneal injection of $50 \mathrm{mg} / \mathrm{kg}$ pentobarbital. ${ }^{18}$ Both kidneys were dissected, cut into smaller pieces and fixed in $10 \%$ neutral buffered formalin overnight at a temperature of $4^{\circ} \mathrm{C}$. Tissue samples were dehydrated in alcohols, cleared in xylol and embedded in paraplast. Tissue sections of $5 \mu \mathrm{m}$ thickness were stained with: haematoxylin and eosin stain, periodic acid Schiff reaction (PAS) counterstained with haematoxylin and Mallory's trichrome stain to demonstrate the microscopic structural changes in the renal cortex. ${ }^{19,20}$ Sections of 4 $\mu \mathrm{m}$ thickness were used for the immunohistochemical study of TGF- $\beta 1$.

\section{Immunohistochemical (IHC) technique for TGF- $\beta 1$}

Kits used: Primary monoclonal Anti- TGF- $\beta 1$ antibody (T 0438) was purchased from Sigma-Aldrich (St. Louis, Mo, USA). The following kits were purchased from Dakocytomation (Glostrup, Denmark); ready-to-use target retrieval solution (S1700), ready-to-use antibody diluent with background reducing components (S3022), and universal detection kits (K 0673).

Steps of TGF- $\beta 1$ immune-staining: Sections were dewaxed in two changes of xylol for 20 minutes, and hydrated in descending grades of alcohol down to distilled water. Sections were immersed in citrate buffer $\left(\mathrm{pH}\right.$ 6) at $95-99^{\circ} \mathrm{C}$ in a water bath for 40 minutes, removed from the bath, and allowed to cool at room temperature. Sections were rinsed with phosphate buffered saline (PBS). Hydrogen peroxide was applied to cover the specimen for 5 minutes, and then the slides were rinsed gently with PBS. Primary antibody at a dilution of 1:50 (according to Manufacturer Company) was applied to the specimens, and incubated for two hours in a humid chamber at room temperature. Slides were rinsed in PBS. Biotinylated link was applied for 10 minutes and sections were rinsed in PBS. Streptavidin HRP reagent was applied for 10 minutes 
and sections were rinsed in PBS. Freshly prepared DAB substrate chromogen solution (1 drop of DAB chromogen $/ 1 \mathrm{ml}$ of substrate buffer) was applied on specimens for 10 minutes. Slides were rinsed gently in distilled water, immersed in haematoxylin for $1 / 2$ minute and rinsed in tap water until blue. Slides were dehydrated in ascending grades of alcohol, cleared in xylol, mounted by Canada balsam and covered with a cover slip. Human colon adenocarcinoma (obtained from the pathology department in our institution) served as a positive control to demonstrate the positive reaction for TGF- $\beta 1$ in the form of brown cytoplasmic granules. ${ }^{21}$ Negative control slides were prepared by the same steps except they were incubated with antibody diluent instead of the primary antibody.

\section{Morphometric study}

Only cross sections of renal corpuscles passing through vascular or urinary poles were considered for the morphometric measurement in renal corpuscles. For each animal, 50 renal corpuscles were analyzed. The surface area of the renal corpuscle and mesangial cells number per glomerulus were determined in sections stained with haematoxylin and eosin. To study the severity of mesangial matrix expansion, the PAS positive mesangial matrix area was quantified in sectioned stained with PAS.
The mesangial matrix fraction was then determined as a percentage $(\%)$ of mesangial PAS positive area per renal corpuscle surface area. ${ }^{22}$ To determine the severity of fibrosis, the $\%$ area of blue stained collagen fibers in Mallory's trichrome stained sections was estimated. Finally, the $\%$ area positively stained with TGF- $\beta 1$ was measured in immune-stained sections. These parameters were assessed in six slides from each specimen examined at a high-power field (x1000 for the mesangial cells number per glomerulus, and $\mathrm{x} 400$ for the rest of parameters). The $\%$ areas were digitized using Olympus ${ }^{\circledR}$ digital camera installed on an Olympus ${ }^{\circledR}$ microscope with $1 / 2 \times$ photo adaptor, using $40 \times$ magnification of an objective lens.

\section{Statistical analysis}

Statistical parameters were expressed as arithmetic mean \pm standard deviation (SD). Student t-test was used to test the significant change in the parameters in different groups of the study in comparison to control group I as well as to test the significance between groups III and IV. Statistical analysis of the data was done by Med Calc software for medical statistics with a statistical significance realized at probability $\mathrm{P}<0.05$. $^{23}$

\section{RESULTS}

Table 1: Mean values \pm S.D of different parameters measured in the groups of the experiment.

\begin{tabular}{|c|c|c|c|c|c|}
\hline Groups of rats: & Group I & Group II & Group III & Group IV & Significance \\
\hline $\begin{array}{l}\text { Mesangial cells number } \\
\text { /glomerulus }\end{array}$ & $\begin{array}{l}22.0352 \pm \\
2.9290\end{array}$ & $\begin{array}{l}21.6741 \pm \\
3.2354\end{array}$ & $\begin{array}{l}45.4508 \pm \\
5.0889\end{array}$ & $\begin{array}{l}28.9444 \pm \\
4.1179\end{array}$ & $\begin{array}{l}\mathrm{P} 1=0.7966 \\
\mathrm{P} 2<0.0001 * \\
\mathrm{P} 3=0.0004 * \\
\mathrm{P} 4<0.0001 *\end{array}$ \\
\hline $\begin{array}{l}\text { Renal corpuscle surface area } \\
\left(10^{4} \times \mu \mathrm{m}^{2}\right)\end{array}$ & $\begin{array}{l}32.2903 \pm \\
5.6200\end{array}$ & $\begin{array}{l}31.5266 \pm \\
6.5557\end{array}$ & $\begin{array}{l}76.8488 \pm \\
10.5126\end{array}$ & $\begin{array}{l}41.0127 \pm \\
5.9111\end{array}$ & $\begin{array}{l}\mathrm{P} 1=0.7829 \\
\mathrm{P} 2<0.0001 * \\
\mathrm{P} 3<0.0033^{*} \\
\mathrm{P} 4<0.0001 *\end{array}$ \\
\hline $\begin{array}{l}\text { Mesangial matrix area in } \\
\text { glomerulus }\left(10^{4} \mathrm{x} \mu \mathrm{m}^{2}\right)\end{array}$ & $\begin{array}{l}6.9669 \pm \\
1.5329\end{array}$ & $\begin{array}{l}6.7250 \pm \\
0.9218\end{array}$ & $\begin{array}{l}43.5770 \pm \\
7.1429\end{array}$ & $\begin{array}{l}15.7674 \pm \\
3.6380\end{array}$ & $\begin{array}{l}\mathrm{P} 1=0.6740 \\
\mathrm{P} 2<0.0001 * \\
\mathrm{P} 3<0.0001 * \\
\mathrm{P} 4<0.0001 *\end{array}$ \\
\hline Mesangial matrix fraction $(\%)$ & $\begin{array}{l}0.2244 \pm \\
0.07198\end{array}$ & $\begin{array}{l}0.2225 \pm \\
0.05820\end{array}$ & $\begin{array}{l}0.5722 \pm \\
0.09058\end{array}$ & $\begin{array}{l}0.3917 \pm 0 \\
09024\end{array}$ & $\begin{array}{l}\mathrm{P} 1=0.9484 \\
\mathrm{P} 2<0.0001 * \\
\mathrm{P} 3=0.0002^{*} \\
\mathrm{P} 4=0.0003 *\end{array}$ \\
\hline $\begin{array}{l}\% \text { Area of blue stained collagen } \\
\text { fibers }\end{array}$ & $\begin{array}{l}0.7086 \pm \\
0.1895\end{array}$ & $\begin{array}{l}0.8283 \pm \\
0.1170\end{array}$ & $\begin{array}{l}28.2891 \pm \\
5.6075\end{array}$ & $\begin{array}{l}5.0649 \pm \\
1.2256\end{array}$ & $\begin{array}{l}\mathrm{P} 1=0.1066 \\
\mathrm{P} 2<0.0001 * \\
\mathrm{P} 3<0.0001 * \\
\mathrm{P} 4<0.0001 *\end{array}$ \\
\hline $\begin{array}{l}\% \text { Area of positive TGF- } \beta 1 \\
\text { immune-stain }\end{array}$ & $\begin{array}{l}0.0012 \pm \\
0.0001\end{array}$ & $\begin{array}{l}0.01010 \pm \\
0.03159\end{array}$ & $\begin{array}{l}33.1606 \pm \\
5.5702\end{array}$ & $\begin{array}{l}8.6699 \pm \\
1.2380\end{array}$ & $\begin{array}{l}\mathrm{P} 1=0.3756 \\
\mathrm{P} 2<0.0001 * \\
\mathrm{P} 3<0.0001 * \\
\mathrm{P} 4<0.0001 *\end{array}$ \\
\hline
\end{tabular}

* Significant change $(\mathrm{P}<0.05)$ by student t-test. $\mathrm{P} 1$ = comparison between group I and group II; $\mathrm{P} 2$ = comparison between group I and group III; P3 = comparison between group I and group IV; P4 = comparison between group III and group IV. 


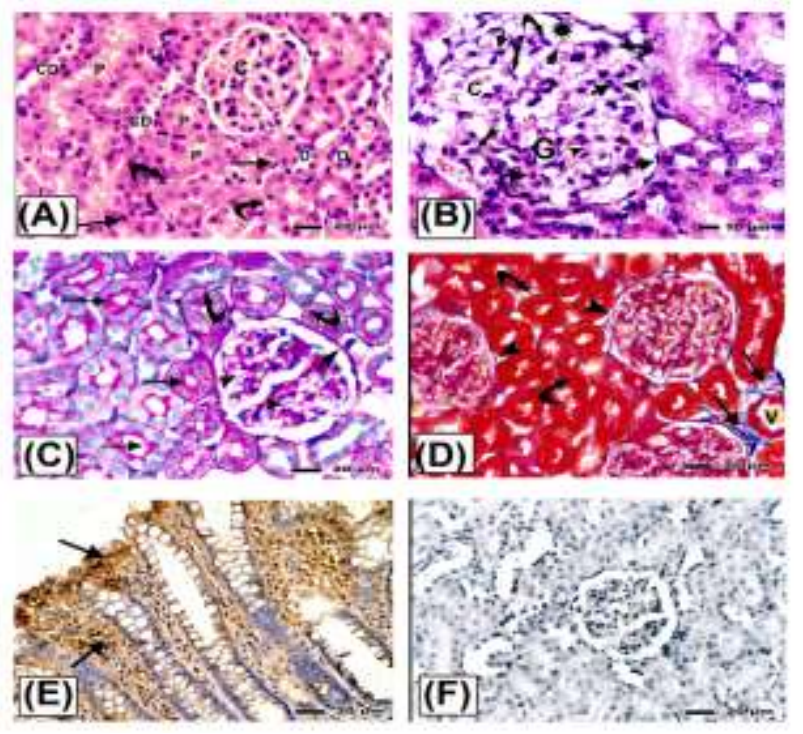

Figure 1: Renal cortex in group I. (A): The renal cortex contains a renal corpuscle (C) Surrounded by proximal convoluted tubules (P) Distal convoluted tubules (D) Collecting ducts (CD) separated by a scares amount interstitium containing blood capillaries (curved arrows) and fibroblasts with flat nuclei (arrows) [H\&E x400]. (B): The renal corpuscle consists of a glomerulus (G) Surrounded by a Bowman's capsule with a filtration space in-between (asterisk). The parietal layer of the capsule is formed of simple squamous cells (arrow), while the visceral layer is formed of podocytes with large oval nuclei (curved arrows). The glomerulus contains tufts of capillaries (C) Lined with flat endothelial cells (tailed arrows). Mesangial cells (short arrows) are surrounded with scanty mesangial matrix (arrow heads) [H\&E x1000]. (C): A positive PAS reaction is seen in the brush border (arrows) of PCT and in the

basement membrane of; renal tubules (curved arrows), renal corpuscles (short arrow), and glomerular capillaries (arrow heads) [PAS reaction x400]. (D): Few blue stained collagen fibres (arrows) are seen in the interstitial connective tissue surrounding a blood vessel ( $v$ ) and in the basement membrane surrounding renal corpuscles (arrow heads) and tubules (curved arrows) [Mallory's trichrome stain $x$ 400]. (E): A positive control slide prepared from human colon carcinoma demonstrates a positive cytoplasmic immune-reaction for TGF- $\beta 1$

(arrows) [IHC for TGF- $\beta 1 \mathrm{x} 400]$. (F): The renal cortex shows a negative immune-reaction for TGF- $\beta 1$ [IHC for TGF- $\beta 1 \times 400]$.

In group I, haematoxylin and eosin stained sections showed that the renal cortex was formed of renal corpuscles and tubules surrounded by a scarce amount of interstitium containing blood capillaries and fibroblasts (Figure 1A). The renal corpuscle consisted of a glomerulus surrounded by a double walled Bowman's capsule with a filtration space in-between. The parietal layer of the capsule was formed of simple squamous cells, while the visceral layer was formed of podocytes with large oval nuclei. The glomerulus contained tufts of capillaries lined with flat endothelial cells. Mesangial cells with small nuclei were observed among the capillaries. They were surrounded by a scanty amount of mesangial matrix (Figure 1B). Renal tubules included proximal convoluted tubules (PCTs), distal convoluted tubules (DCTs) and collecting ducts (CDs). The PCTs were characterized by a narrow lumen. They were lined with a single layer of tall pyramidal cells with abundant deeply acidophilic cytoplasm and basal large vesicular rounded nuclei. The DCTs showed a wider lumen. They were lined with simple cuboidal cells with central rounded vesicular nuclei. Collecting ducts were lined with cuboidal epithelium that showed a pale cytoplasm and distinct cell boundaries (Figure 1A). Sections stained with PAS reaction demonstrated a strong PAS reaction in the brush border of PCTs and in the basement membrane of; renal tubules, renal corpuscle and glomerular capillaries (Figure 1C). Sections stained with Mallory's trichrome showed the presence of few blue stained collagen fibres in the interstitial connective tissue and in the basement membrane surrounding renal corpuscles and tubules (Figure 1D). Human colon carcinoma was used as a positive control for TGF- $\beta 1$ in the form of brown cytoplasmic granules (Figure 1E). In group I, a negative immune-reaction for TGF- $\beta 1$ was seen in the renal cortex (Figure 1F).

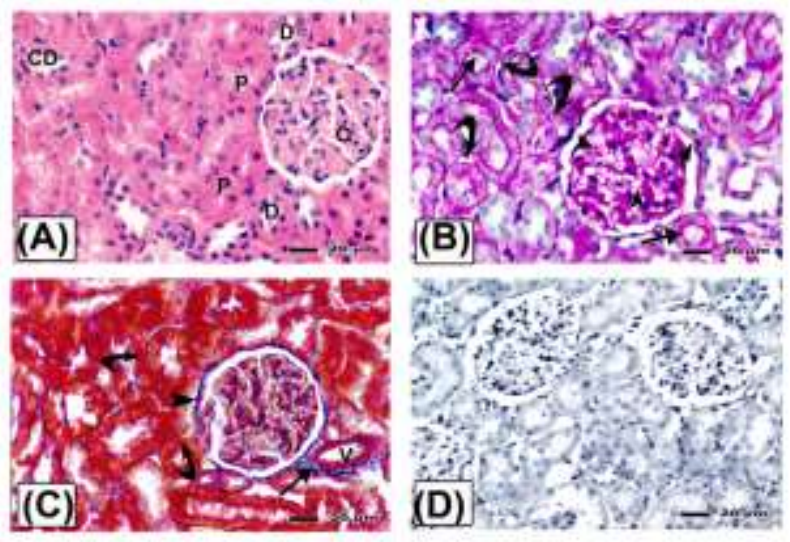

Figure 2: Renal cortex in group II. (A): A renal corpuscle (C) is surrounded by proximal convoluted tubules (P), distal convoluted tubules (D) and collecting ducts (CD) [H\&E x400]. (B): A positive PAS reaction is seen in the brush border (arrows) of PCT and in the basement membrane of; renal tubules (curved arrows), renal corpuscles (short arrow) and glomerular capillaries (arrow heads) [PAS reaction x400]. (C): Few collagen fibres (arrow) are seen in the interstitial connective tissue surrounding a blood vessel ( $v$ ) in the basement membrane of a renal corpuscle (arrow head) and tubules (curved arrows) [Mallory's trichrome stain x 400]. (D): Renal cortex shows a negative immune-reaction for TGF- $\beta 1$ [IHC for TGF- $\beta 1 \times 400]$. 
In group II, no microscopic structural (Figure 2) or statistical (Table 1) differences were observed in the renal cortex of the rats in group II as compared to group I.
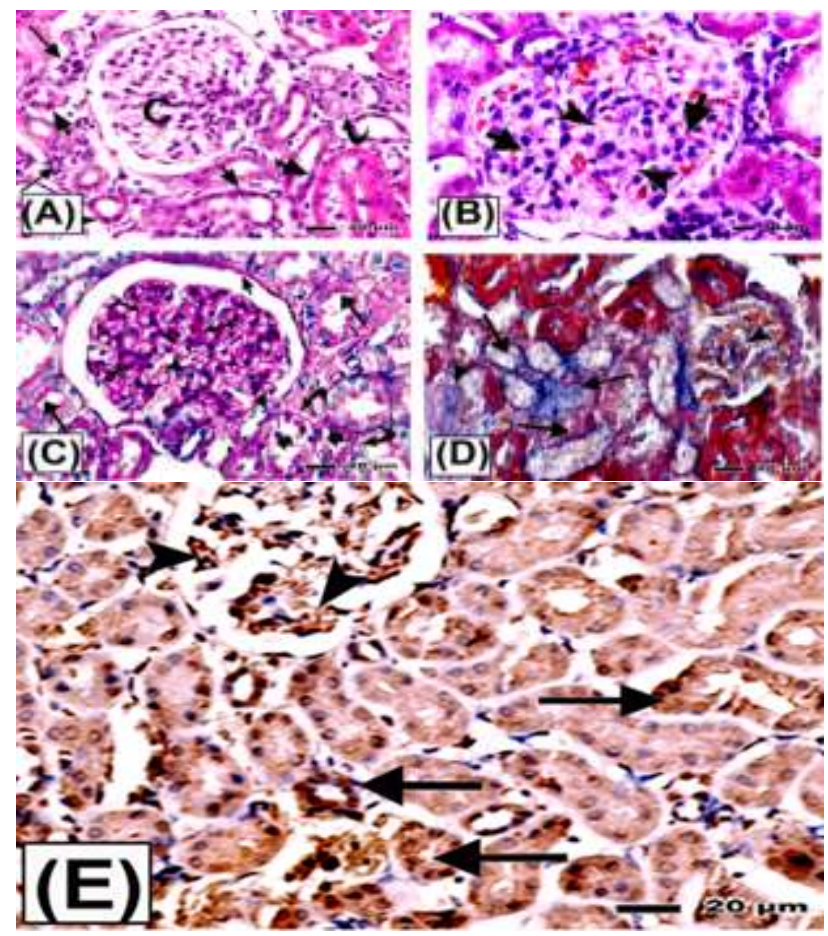

Figure 3: Renal cortex in group III. (A):

Hypertrophied renal corpuscle (c) surrounded by degenerated renal tubules with deep acidophilic cytoplasm and dense pyknotic (short arrows) or

karyolytic (curved arrow) nuclei. Excess inflammatory cells infiltrations (arrows) are seen in the interstitium surrounding renal corpuscle and tubules [H\&E x400]. (B): Hypertrophied renal corpuscle shows mesangial hyper-cellularity (short arrows) among expanded mesangial matrix (arrow heads) [H\&E x1000].(C): A positive $\mathrm{PAS}$ reaction is seen in the expanded mesangial matrix (tailed arrows) of a hypertrophied renal corpuscle, and in the thickened basement membrane of; glomerular capillaries (arrow heads) and affected renal corpuscle (short arrow) and tubules (curved arrows). Some

PCTs show a loss of the brush border (thick arrows), while others show a PAS positive brush border (arrows) [PAS reaction $x 400]$. (D): Excess blue stained collagen fibres are evident in the interstitium surrounding degenerated renal tubules (arrows) and within an affected renal corpuscle (arrow heads) [Mallory's trichrome stain $x$ 400]. (E): A positive immune-reaction for TGF- $\beta 1$ is detected in a renal corpuscle (arrow heads) and in degenerated tubules (arrows) [IHC for TGF- $\beta 1 \times 400]$.

In group III, sections stained with haematoxylin and eosin in diabetic rats showed the presence of hypertrophied renal corpuscles with mesangial hypercellularity among expanded mesangial matrix (Figure 3 $\mathrm{A}, \mathrm{B})$. A significant $(\mathrm{P}<0.05)$ increase in the mean values of both renal corpuscle surface area and the number of mesangial cells per glomerulus were detected in this group as compared to control group I (Table 1). Degenerated renal tubules were lined with epithelium showing deep acidophilic cytoplasm and dense pyknotic or even karyolytic nuclei. Excess inflammatory cells infiltration was detected in the renal interstitium surrounding renal corpuscles and tubules (Figure 3A). In sections stained with PAS, a number of PCTs showed a decrease in the PAS reaction and loss of the brush border. The basement membrane of glomerular capillaries, affected renal corpuscles and tubules appeared thickened with a positive PAS reaction. Expanded mesangial matrix in hypertrophied renal corpuscles showed a strong positive PAS reaction (Figure $3 \mathrm{C}$ ). The mean value of the mesangial matrix fraction in renal corpuscles was significantly $(\mathrm{P}<0.05)$ increased as compared to group I (Table 1). Section stained with Mallory's trichrome revealed the presence of excess blue stained collagen fibres in the interstitium surrounding degenerated renal tubules and within the affected renal corpuscles (Figure $3 \mathrm{D})$. The mean value of the $\%$ area of blue stained collagen fibres was significantly $(\mathrm{P}<0.05)$ increased as compared to group I (Table 1). A positive immunereaction for TGF- $\beta 1$ was detected in affected renal corpuscles and in degenerated renal tubules (Figure 3E). The mean value of the \% area of the positive immunestain for TGF- $\beta 1$ was significantly $(\mathrm{P}<0.05)$ increased in this group as compared to group I (Table 1).

In group IV, the microscopic structural changes were relatively ameliorated as compared with diabetic rats in group III. A significant $(\mathrm{P}<0.05)$ decrease in the mean values of renal corpuscle surface area and mesangial cells number per glomerulus were detected in group IV as compared to group III. However, both parameters were still significantly $(\mathrm{P}<0.05)$ higher than control group I (Table 1). Most of the renal tubules were lined with epithelium showing vesicular nuclei. However, few renal tubules appeared degenerated with pyknotic nuclei. Some inflammatory cells infiltration was still detected in the interstitium (Figure 4A). Sections stained with PAS reaction revealed the presence of PAS positive brush border in most of the PCTs. The basement membranes of glomerular capillaries, renal corpuscles and tubules were not thickened (Figure 4B). The mean value of mesangial matrix fraction in the renal corpuscles was significantly $(\mathrm{P}<0.05)$ decreased as compared to group III (Table 1). Sections stained with Mallory's trichrome revealed some collagen fibres in the renal interstitium surrounding affected tubules. Renal corpuscles showed few collagen fibres (Figure 4 C). The mean value of the $\%$ area of blue stained collagen fibres was significantly $(\mathrm{P}<0.05)$ decreased as compared to group III (Table 1). A positive TGF$\beta 1$ immune-reaction was seen in few cells in renal corpuscles and tubules (Figure 4D). The \% area of the positive TGF- $\beta 1$ immune-stain was significantly $(\mathrm{P}<0.05)$ decreased in this group as compared to group III (Table 1). 


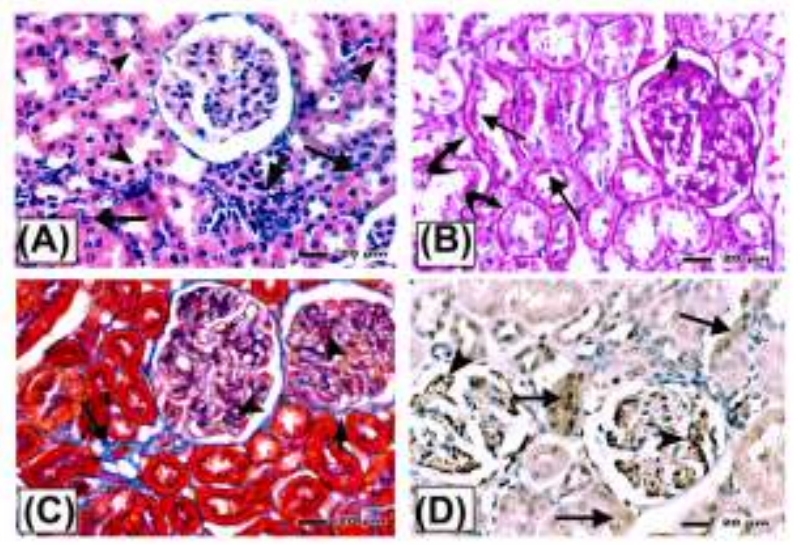

Figure 4: Renal cortex in group IV. (A): Most of renal tubules are lined with epithelium showing vesicular nuclei (arrows). Dense pyknotic (arrow heads) nuclei are seen in few renal tubules. Note the inflammatory cells infiltration (short arrow) in the renal interstitium

[H\&E x400]. (B): Most of the PCTs show a PAS positive brush border (arrows). A positive PAS reaction is seen in the basement membrane of a renal corpuscle (short arrow) and tubules (curved arrows)

[PAS reaction $x 400]$. $(C)$ : Some collagen fibres are seen in the interstitium surrounding renal corpuscles (short arrow) and tubule (arrow). Few collagen fibres are seen within the renal corpuscles (arrow heads) [Mallory's trichrome stain $x$ 400]. (D): Few cells in renal corpuscles (arrow heads) and tubules (arrows) show a positive immune-reaction for TGF- $\beta 1$ [IHC for TGF- $\beta 1 \times 400]$.

\section{DISCUSSION}

In the current study, the renal cortex of group III revealed microscopic structural changes of diabetic nephropathy in the form of; hypertrophied renal corpuscles, expanded PAS positive mesangial matrix and thickening of the glomerular and tubular basement membranes. It is believed that the renal hypertrophy and the deposition of extracellular mesangial matrix in diabetic nephropathy lead to glomerulosclerosis. Consequently, albuminuria, high blood pressure, a progressive decrease in glomerular filtration rate, uremia, and end-stage renal disease are the intermediate and long-term outcomes of the disease. ${ }^{24}$ In diabetic rats of group III, inflammatory cells infiltration was found in the renal interstitium. A growing body of evidence suggests the role of inflammatory cells in the development of diabetic nephropathy. ${ }^{25}$ Inflammatory cells migration into the kidney is considered as a crucial step in the progression of the disease through the production of various reactive oxygen species (ROS), growth factors and pro-inflammatory cytokines. ${ }^{26}$ Among such cytokines, the transforming growth factor- $\beta 1$ (TGF$\beta 1)$ is believed to have a central role as a mediator in the fibrogenic process of diabetic nephropathy. ${ }^{27}$ In the current study, TGF- $\beta 1$ was not detected in the renal cortex of control group I. On the other hand, diabetic rats in group III showed a positive TGF- $\beta 1$ immune-reaction in affected renal corpuscles and tubules. In agreement with that, Ina et al have demonstrated that TGF- $\beta 1$ is expressed in diabetic kidney, but not in the normal kidney. The hyperglycemia, commonly observed in diabetic patients, has been associated with an upregulation of glucose transport-1 which leads to TGF- $\beta 1$ over-expression by mesangial and tubular cells. Increased intra-glomerular pressure, activation of the reninangiotensin system, advanced glycation end products and ROS have been shown to induce TGF- $\beta 1$ production in the kidney or in cultured mesangial or tubular cells. ${ }^{29}$ It has been demonstrated that a sustained over-expression of TGF- $\beta 1$ stimulates autophagy and loss of tubular epithelial cells, causing tubular atrophy. ${ }^{30}$ This may explain the presence of degenerated renal tubules in group III of the present study.

In the current study, fibrotic changes were encountered in renal corpuscles and in the tubulo-interstitium of group III diabetic rats. Interstitial fibrosis contributes to the deterioration of renal function, especially during the later stages of diabetic nephropathy. ${ }^{31}$ The etiology of renal fibrosis has been linked to TGF- $\beta 1$. It has been reported that the generation of TGF- $\beta 1$ by the cells of the proximal convoluted tubules may have adverse autocrine effects on the epithelial cell in addition to its paracrine effects on the interstitial cells. ${ }^{32}$ Tubular over-expression of TGF- $\beta 1$ results in proliferation of peri-tubular cells and deposition of collagen by matrix-producing myofibroblasts. ${ }^{30}$ Yet, there is still no effective drug or therapy to prevent or treat the patients with renal fibrosis. However, interventions to block TGF- $\beta 1$ production in the kidney could be suggested as a therapeutic target to control fibrosis in diabetic nephropathy. ${ }^{30}$

The current study was carried on to investigate the effect of nab-paclitaxel in diabetic nephropathy. The administration of the drug alone in group II rats did not alter the kidney structure. Preclinical and clinical data have demonstrated a safety margin of nab-paclitaxel over solvent-based paclitaxel. ${ }^{33}$ The administration of nabpaclitaxel in group IV diabetic rats partially ameliorated the histopathological changes of diabetic nephropathy encountered in the renal cortex as compared to diabetic rats in group III. The mesangial cellularity was significantly reduced than in group III. Renal tubules were generally preserved apart from some tubules that were lined with cells showing pyknotic nuclei. In addition, the drug significantly reduced glomerular and tubulo-interstitial fibrosis.

No available literature described the effect of nabpaclitaxel in diabetic nephropathy. However, different studies demonstrated that the treatment of nab-paclitaxel in human successfully decreased fibrosis and reduced the desmoplastic stroma in certain resistant tumors. ${ }^{34}$ Furthermore, type I collagen analysis of tumour tissue samples from patients treated with nab-paclitaxel revealed a less abundant fibrillar collagen matrix around tumor glands. ${ }^{35}$ 
In the current study, the immune-expression of TGF- $\beta 1$ showed a significant decrease in group IV diabetic rats treated with nab-paclitaxel in comparison to group III diabetic rats. No available literature demonstrated an effect of nab-paclitaxel on TGF- $\beta 1$ immune-expression in cases of diabetic nephropathy. However, many studies showed that the standard solvent-based paclitaxel formula exerts an anti-fibrotic effect through inhibiting TGF$\beta 1 .^{6,36}$ The primary mechanism of action of paclitaxel is mediated through the suppression of microtubule spindle dynamics, by stabilizing microtubules. ${ }^{37}$ Paclitaxel therefore provides an inhibitory effect to TGF- $\beta$ signaling in fibrosis as it has been reported that low-dose paclitaxel reduced pulmonary fibrosis in rat bleomycin induced pulmonary fibrosis model by blocking the TGF- $\beta 1{ }^{38}$ In the kidneys, the administration of low-dose paclitaxel has significantly reduced tubulo-interstitial fibrosis in a rat model of unilateral ureteral obstruction model. ${ }^{39}, 40$ Furthermore, following a subtotal renal ablation in rats, low-dose paclitaxel showed a significant reno-protective role by inhibiting TGF- $\beta$ signaling. ${ }^{36}$

In conclusion, the present study demonstrated that nabpaclitaxel partially ameliorated the microscopic structural changes encountered in the renal cortex of adult rats with diabetic nephropathy and decreased the immuneexpression of the fibrogenic mediator TGF- $\beta 1$, suggesting a partial reno-protective effect of nabpaclitaxel in cases of diabetic nephropathy.

\section{Funding: No funding sources}

Conflict of interest: None declared

Ethical approval: The study was approved by the institutional ethics committee of Mansoura Faculty of Medicine, Egypt

\section{REFERENCES}

1. Gray S, Cooper M. Diabetic nephropathy in 2010: Alleviating the burden of diabetic nephropathy. Nat Rev Nephrol. 2011;7(2):71-3.

2. Fioretto P, Mauer M. Histopathology of diabetic nephropathy. Semin Nephrol. 2007;27(2):195-207.

3. Hills C, Squires P. TGF-beta1-induced epithelial-tomesenchymal transition and therapeutic intervention in diabetic nephropathy. Am J Nephrol. 2010;31:6874.

4. Srivastava S, Koya D, Kanasaki K. MicroRNAs in kidney fibrosis and diabetic nephropathy: roles on EMT and EndMT. Biomed Res Int. 2013:125469.

5. Dai C, Liu Y: Hepatocyte growth factor antagonizes the profibrotic action of TGF- $\beta 1$ in mesangial cells by stabilizing Smad transcriptional corepressor TGIF. J Am Soc Nephrol. 2004;15:1402-12.

6. Zhou J, Zhong D, Wang Q, Miao X, Xu X. Paclitaxel ameliorates fibrosis in hepatic stellate cells via inhibition of TGF- $\beta /$ Smad activity. World J Gasteroenterol. 2010;16 (26):3330-4.
7. Zhang D, Yang, R, Wang S, Dong Z. Paclitaxel: new uses for an old drug. Drug Des Devel Ther. 2014;20(8):279-84.

8. Khanna C, Rosenberg M, Vail D. A Review of Paclitaxel and Novel Formulations Including Those Suitable for Use in Dogs. J Vet Intern Med. 2015;29(4):1006-12.

9. Stinchcombe T. Nanoparticle albumin-bound paclitaxel: a novel Cremphor-EL-free formulation of paclitaxel. Nanomedicine (Lond). 2007;2(4):41523.

10. Desai N, Trieu V, Yao Z, Louie L, Ci S, Yang A. et al. Increased antitumor activity, intratumor paclitaxel concentrations, and endothelial cell transport of cremophor-free, albumin-bound paclitaxel, ABI-007, compared with cremophorbased paclitaxel. Clin Cancer Res. 2006;12:1317-24.

11. Gradishar W. Albumin-bound paclitaxel: a nextgeneration taxane. Expert Opinion on Pharmacotherapy. 2006;7(8):1041-53.

12. Liu X, Zhu S, Wang T, Hummers L, Wigley F, Goldschmidt-Clermont P. et al. Paclitaxel modulates TGF- $\beta$ signaling in scleroderma skin grafts in immunodeficient mice. PLoS Med. 2005;2(12):e354

13. Grube E, Dawkins K, Guagliumi G, Banning A, Zmudka K, Colombo A, et al. TAXUS VI final 5year results: a multicentre, randomised trial comparing polymer-based moderate-release paclitaxel-eluting stent with a bare metal stent for treatment of long, complex coronary artery lesions. EuroIntervention. 2009;4(5):572-7.

14. Hellal F, Hurtado A, Ruschel J, Flynn K, Laskowski $\mathrm{C}$, Umlauf $\mathrm{M}$, et al. Microtubule stabilization reduces scarring and causes axon regeneration after spinal cord injury. Science. 2011;331(6019):928-31.

15. Leehey D, Singh A, Bast J, Sethupathi P, Singh R. Glomerular renin angiotensin system in streptozotocin diabetic and Zucker diabetic fatty rats. Transl Res. 2008;151(4):208-16.

16. Michael S, Ganesh R, Viswanathan P. Effect of long acting insulin supplementation on diabetic nephropathy in Wistar rats. Indian $\mathbf{J}$ Exp Biol. 2012;50(12):867-74.

17. Yamashita Y, Egashira N, Masuguchi K, Ushio S, Kawashiri T, and Oishi R, "Comparison of peripheral neuropathy induced by standard and nanoparticle albumin-bound paclitaxel in rats," J Pharmacol Sci. 2011;117(2):116-20.

18. Chen H, Brahmbhatt S, Gupta A and Sharma A. Duration of streptozotocin-induced diabetes differentially affects p38-mitogen-activated protein kinase (MAPK) phosphorylation in renal and vascular dysfunction. Cardiovascular Diabetology. 2005;4(1):3-11.

19. SuvarnaK, LaytonC, Bancroft J. Theory and Practice of Histological Techniques, 7th ed. Philadelphia, USA: Churchill Livingstone of Elsevier; 2013:173-214. 
20. Kiernan J. Histological and Histochemical Methods: Theory and Practice. 4th ed. Bloxham UK, Scion; 2008:190-213.

21. Sulkowski S, Wincewicz A, Sulkowska M, Koda M. Transforming growth factor-betal and regulators of apoptosis. Ann N Y Acad Sci. 2009;1171:116-23.

22. Matsubara T, Abe H, Arai H, Nagai K, Mima A, Kanamori H, et al. Expression of Smad1 is directly associated with mesangial matrix expansion in rat diabetic nephropathy. Lab Invest. 2006;86(4):35768.

23. Schoonjans F., Zalata A., Depuydt C. and Comhaire F. MedCalc: a new computer program for medical statistics. Computer Methods and programs in Biomedicine. 1995;48:257-62.

24. Goldberg R. Cytokine and cytokine-like inflammation markers, endothelial dysfunction, and imbalanced coagulation in development of diabetes and its complications. J Clin Endocrinol Metab. 2009;94(9):3171-82.

25. Galkina E and Ley K. Leukocyte recruitment and vascular injury in diabetic nephropathy. J Am Soc Nephrol. 2006;17(2):368-77.

26. Wada J, Makino $H$. Inflammation and the pathogenesis of diabetic nephropathy. Clin Sci (Lond). 2013;124(3):139-52.

27. Chang A, Hathaway C, Smithies O, Kakoki M. Transforming growth factor $\beta 1$ and diabetic nephropathy. Am J Physiol Renal Physiol 2015:ajprenal.00502.2015.

28. Ina $\mathrm{K}$, Kitamura $\mathrm{H}$, Tatsukawa $\mathrm{S}$, Takayama $\mathrm{T}$, Fujikura Y, Shimada T. Transformation of interstitial fibroblasts and tubulointerstitial fibrosis in diabetic nephropathy. Med Electron Microsc 2002;35(2):87-95.

29. Qian Y, Feldman E, Pennathur S, Kretzler M, and Brosius F. "From fibrosis to sclerosis: mechanisms of glomerulosclerosis in diabetic nephropathy," Diabetes. 2008;57(6):1439-45.

30. Bonventre J. Can we target tubular damage to prevent renal function decline in diabetes? Semin Nephrol. 2012;32(5):452-62.

31. Katz A, Caramori M, Sisson-Ross S, Groppoli T, Basgen J, Mauer M. An increase in the cell component of the cortical interstitium antedates interstitial fibrosis in type 1 diabetic patients. Kidney Int. 2002;61:2058-66.

32. Koesters R, Kaissling B, Lehir M, Picard N, Theilig F, Gebhardt R, et al. Tubular overexpression of transforming growth factor-betal induces autophagy and fibrosis but not mesenchymal transition of renal epithelial cells. Am J Pathol. 2010;177(2):632-43.

33. Gradishar W, Tjulandin S, Davidson N, Shaw H, Desai N, Bhar P, et al. Phase III trial of nanoparticle albumin-bound paclitaxel compared with polyethylated castor oil-based paclitaxel in women with breast cancer. J Clin Oncol. 2005;23:7794-803.

34. Von Hoff D, Ramanathan R, Borad M, Laheru D, Smith L, Wood T, et al. Gemcitabine plus nabpaclitaxel is an active regimen in patients with advanced pancreatic cancer: a phase I/II trial. J Clin Oncol. 2011;29(34):4548-54.

35. Alvarez R, Musteanu M, Garcia-Garcia E, LopezCasas P, Megias D, Guerra C, et al. Stromal disrupting effects of nab-paclitaxel in pancreatic cancer. Br J Cancer. 2013;109(4):926-33.

36. Sun L, Zhang D, Liu F, Xiang X, Ling G, Xiao L, et al. Low-dose paclitaxel ameliorates fibrosis in the remnant kidney model by down-regulating miR192. J Pathol. 2011;225(3):364-77.

37. Jordan M, Wilson L. Microtubules as a target for anticancer drugs. Nat Rev Cancer 2004;4(4):253-65.

38. Wang C, Song X, Li Y, Han F, Gao S, Wang X, et al. Low-dose paclitaxel ameliorates pulmonary fibrosis by suppressing TGF- $\beta 1 /$ Smad3 pathway via miR-140 upregulation. PLoS One. 2013;8(8):e70725.

39. Zhang D, Sun L, Xian W, Liu F, Ling G, Xiao L, et al. Low-dose paclitaxel ameliorates renal fibrosis in rat UUO model by inhibition of TGF- $\beta / \mathrm{Smad}$ activity. Lab Invest. 2010;90(3):436-47.

40. Karbalay-Doust S, Noorafshan A, Pourshahid S. Taxol and taurine protect the renal tissue of rats after unilateral ureteral obstruction: a stereological survey. Korean J Urol. 2012;53(5):360-7.

Cite this article as: Mazroa SA, Asker SA. Impact of nanoparticle albumin-bound paclitaxel on microscopic structure and immunohistochemical expression of transforming growth factor- $\beta 1$ in the renal cortex of rat diabetic nephropathy. Int J Sci Rep 2016;2(5):86-93. 